\title{
An integrated IO and CGE approach to analysing changes in environmental trade balances
}

by

Karen Turner $^{a} *$, Michelle Gilmartin ${ }^{b}$, Peter G. McGregor ${ }^{b}$, and J. Kim Swales ${ }^{b}$

a. Division of Economics, Stirling Management School, University of Stirling, Stirling, karen.turner@stir.ac.uk,0044 (0) 1786467474

b. Fraser of Allander Institute, Department of Economics, University of Strathclyde

*Corresponding author

\section{Accepted for publication in Papers in Regional Science, February 2011}

\section{Acknowledgements}

The research reported here is an output of Karen Turner's ESRC Climate Change Leadership Fellowship (Grant reference RES-066-27-0029). However, this research builds and draws liberally on research funded by the EPSRC through the SuperGen Marine Energy Research Consortium (Grant reference: EP/EO40136/1). We are grateful to participants at the International Input-Output Association Meeting on Managing the Environment (Seville, July 2008), the $48^{\text {th }}$ Annual Meeting of the Western Regional Science Association (Napa Valley, California, February 2009) and a seminar at the University of Dundee (March 2009) for comments and useful suggestions on earlier versions of this paper. We are also grateful to two anonymous referees for their comments on the intial submission of this paper. 


\section{Abstract}

The application of multi-region environmental input-output (IO) analysis to the problem of accounting for emissions generation (and/or resource use) under different accounting principles has become increasingly common in the ecological and environmental economics literature, with many applications at the international but fewer at the interregional sub-national level. As an accounting framework, IO tables and IO demand-driven multiplier techniques are absolutely appropriate for conventional pollution attribution analyses because they provide all the required information on pollution embodied in intersectoral interactions and interregional trade flows. However, as a model of how the economy moves from one equilibrium to another in response to a marginal change in activity, IO is unlikely to be appropriate because it is only a very special case of a wider set of general equilibrium approaches. Here, we combine IO accounting with interregional computable general equilibrium (CGE) modelling, adopting Scotland and the rest of the UK as an example. We use the CGE framework to model the impacts of a change in activity and IO analysis for the accounting/attribution analysis of pollution embodied in interregional trade flows (and the interregional $\mathrm{CO} 2$ 'trade balance') before and after the change is introduced.

Keywords: Regional CGE modelling, interregional input-output, $\mathrm{CO} 2$ trade balance, environmental attribution

JEL Classifications: D57, D58, R15, Q56 


\section{Introduction}

Input-output (IO) analysis is a powerful accounting tool for examining the structure of economic activity and associated issues such as the pollution and/or resource use engendered or embodied, directly or indirectly, in production, consumption and trade flows under different accounting principles (Munksgaard and Pedersen, 2001). Particularly in the ecological footprint literature, where focus is on accounting for emissions under the consumption accounting principle, IO analysis has become an increasingly commonly used technique to measure and allocate responsibility for emissions generation (see Wiedmann et al., 2007, Wiedmann, 2009, for reviews). As explained by Turner et al. (2007) this would seem a natural development, given that the focus of ecological or carbon footprints is to capture the total (direct plus indirect) resource use or emissions embodied in final consumption in an economy. IO analysis is based around a set of sectorally disaggregated economic accounts, where inputs to each industrial sector, and the subsequent uses of the output of those sectors, are separately identified. Therefore, by the use of straightforward mathematical routines, the interdependence of different activities can be quantified, and all direct, indirect and, where appropriate, induced, resource use embodied within consumption can be tracked (Leontief, 1970, Miller and Blair, $1985,2009)$.

Turner et al. (2007) go on to derive a multi-region IO method that is appropriate for accounting for emissions under the production and consumption accounting principles and determining environmental trade balances. Most applications to date have had an international focus. However, pollution accounting is also important at a sub-national regional level where there is devolution of responsibility for setting and achieving environmental or sustainability objectives. For example, in McGregor et al (2008) we apply the interregional IO accounting method, as derived in Turner et al (2007), to the case of Scotland and the rest of the UK, and to the US Midwest in Ha et al (2009). 
However, while IO is accepted in the literature as perhaps the only way of clearly accounting for pollution supported by economic activity, there is no agreement that IO is an appropriate method of modelling changes in conditions. Where concern lies in analysing the impacts of changes in policy, or other disturbances, on variables of interest, such as environmental trade balances, a more flexible non-IO framework is required, but one that maintains consistency with the IO accounting framework. Such a framework should allow us to model both supply and demand side behaviour, and prices and quantities simultaneously and endogenously. An approach that incorporates the main strengths of $\mathrm{IO}$ for the treatment of environmental problems - i.e. the multi-sectoral, system wide features of IO tables - but builds a more flexible analytical framework around this is computable general equilibrium (CGE) modelling. CGE modelling is now firmly established in the academic literature as the dominant approach for analysing global, national and regional environmental issues (see, for example, Bergman, 1988, Beausejour et al., 1995, Conrad, 1999, Welsch, 1996, Wissema and Dellink 2007). Single region/nation environmental CGE models based on the AMOS framework initially developed by Harrigan et al (1991) have been generated for Scotland (Anson and Turner, 2009, and Hanley et al, 2006, 2009) and the UK (Allan et al, 2007a, and Turner, 2009). However, in order to analyse issues relating to environmental trade balances between the regions of the UK, and between the UK and the rest of the world, an interregional CGE modelling framework is required. While interregional CGE models are fairly commonly applied at the international level, they are less well developed at the sub-national level and have not, to our knowledge, been employed to extend the resource use/pollution accounting and environmental trade balance analysis that has become common in the IO literature.

In this paper we build on 2-region IO analysis in McGregor et al (2008). We demonstrate the potential added value in combing CGE and IO techniques in order to quantify the impact on environmental or pollution 'trade balances' associated with changes in economic activity. We develop a very simple 2-region, 3-sector variant of the UK AMOS framework for Scotland and 
the rest of the UK (see Gilmartin et al. 2007a,b; McGregor et al, 1999) to conduct some illustrative analysis for a simple demand disturbance and demonstrate the potential contribution of interregional CGE modelling techniques to environmental trade balance analysis. ${ }^{1} \mathrm{We}$ demonstrate how alternative specifications of a key element of supply-side behaviour at the regional and national levels, wage determination, effect model results, including the impact on the interregional $\mathrm{CO} 2$ 'trade balance'. We do this by using CGE results to estimate post-shock IO tables and calculate the pollution content of interregional trade flows in each year after the demand shock (an increase in export demand in one region) is introduced as the economy adjusts to a new long-run equilibrium.

Note that the IO accounting analysis in this paper is based on the standard Type I approach generally adopted in the literature where household consumption is an exogenous driver of polluting activity. However, in analysing changes in activity within the CGE modelling framework, we are able to capture income and consumption effects from endogenous changes in household activity (which would be captured in a Type II IO analysis, but with the loss of household consumption as a driver of polluting activity throughout the economy). We then revert to Type I IO analysis in the post-shock accounting exercise.

The remainder of the paper is structured as follows. In Section 2 we use the interregional IO accounting technique proposed by Turner et al (2007) to calculate the base year (1999) CO2 trade balance between Scotland and the rest of the UK (RUK). In Section 3 we introduce our illustrative AMOSRUK interregional CGE model and report the results of introducing a $10 \%$ increase in export demand from the rest of the world (ROW) to one of the production sectors in RUK under different assumptions about wage setting behaviour. A summary and conclusions are provided in Section 4.

\footnotetext{
${ }^{1}$ We are currently engaged in a project (part of the UK Economic and Social Research Council's Climate Change Leadership Fellowship programme) to develop a more useful empirical IO and CGE framework with a greater degree of spatial and sectoral disaggregation.
} 


\section{Input-output analysis of pollution trade balances - an illustrative application for Scotland and the rest of the UK (RUK)}

\subsection{The interregional IO frame work}

We apply the 2-region framework derived in Turner et al., (2007) to demonstrate an analytical IO method for enumerating the pollution content of interregional trade flows. The basic 2region framework is shown in equation $(1){ }^{2}$

(1) $\left(\begin{array}{ll}\mathbf{x}_{11} & \mathbf{x}_{12} \\ \mathbf{x}_{21} & \mathbf{x}_{22}\end{array}\right)=\left(\begin{array}{cc}\mathbf{I}-\mathbf{A}_{11} & -\mathbf{A}_{12} \\ -\mathbf{A}_{21} & \mathbf{I}-\mathbf{A}_{22}\end{array}\right)^{-1}\left(\begin{array}{ll}\mathbf{y}_{11} & \mathbf{y}_{12} \\ \mathbf{y}_{21} & \mathbf{y}_{22}\end{array}\right)$

Final demand is presented as a matrix with separate elements for: local final demand in region 1 for commodities produced in region $1\left(\mathbf{y}_{11}\right)$; local (exogenous) final demand in region 2 for commodities produced in region $2\left(\mathbf{y}_{22}\right)$; direct exports to exogenous final demand in region 2 of commodities produced in region $1\left(\mathbf{y}_{12}\right)$ (endogenous intermediate export demand in region 2 for region 1 commodities is given by $\mathbf{A}_{\mathbf{1 2}}$ ); and direct exports to exogenous final demand in region 1 of commodities produced in region $2\left(\mathbf{y}_{21}\right)$. Thus, $\mathbf{x}_{\mathbf{i j}}$ is an $\mathrm{N} \times 1$ vector giving output of sectors in region $i$ generated by the consumption demands (domestic and imports) of region $j$.

In our illustrative analysis, Scotland is assumed to be region 1 and the rest of the UK is assumed to be region 2. The framework is aggregated to 3 sectors to allow for compatibility with the 3 sector interregional CGE model, AMOSRUK. Each region therefore has $i=1, \ldots, N=3$ production sectors where each sector produces only one commodity. Submatrices $\mathbf{A}_{\mathbf{r s}}$ contain elements $a_{i j}^{r s}$, describing the transactions between production sector $i$ in producing region $r$ and

\footnotetext{
${ }^{2}$ See Allan et al. (2004) for an extension to a multi-region framework.
} 
consuming sector $j$ in consuming region $s$, for each unit output of sector $j$ in region $s$. [I A $]^{-1}$ is the partitioned interregional Leontief inverse. Using a similar notation to that used for the single region model, $b_{i j}^{r s}$ is the output required in industry $i$ in region $r$ per monetary unit of final demand for industry $j$ in regions $s$. Thus by partitioning the A-matrix so as to identify intermediate inputs production in the own and other region, and by separating the $\mathbf{y}$ vector final demand into commodities produced in the own and other region, it is therefore possible to identify how exogenous demand in one region affects activity in the other region.

As for the single region case, this framework can be extended to consider the issue of pollution spillovers between two regions. Equation (1) is augmented with $(1 \times N)$ vectors of outputpollution coefficients for a single pollutant $\left(\mathrm{CO}_{2}\right), \mathbf{\Phi}_{\mathbf{r}}^{\mathbf{x}}$. Each shows the direct $\mathrm{CO}_{2}$ intensity of output in each production sector $i$ for an individual region, $r$ :

$$
\text { (2) } \begin{aligned}
\left(\begin{array}{cc}
\mathrm{f}_{11}^{\mathrm{x}} & \mathrm{f}_{12}^{\mathrm{x}} \\
\mathrm{f}_{21}^{\mathrm{x}} & \mathrm{f}_{22}^{\mathrm{x}}
\end{array}\right) & =\left(\begin{array}{cc}
\boldsymbol{\Phi}_{1}^{\mathrm{x}} & 0 \\
0 & \boldsymbol{\Phi}_{2}^{\mathrm{x}}
\end{array}\right)\left(\begin{array}{cc}
\mathbf{I}-\mathbf{A}_{11} & -\mathbf{A}_{12} \\
-\mathbf{A}_{21} & \mathbf{I}-\mathbf{A}_{22}
\end{array}\right)^{-1}\left(\begin{array}{ll}
\mathbf{y}_{11} & \mathbf{y}_{12} \\
\mathbf{y}_{21} & \mathbf{y}_{22}
\end{array}\right) \\
& =\left(\begin{array}{ll}
\boldsymbol{\Phi}_{1}^{\mathbf{x}} \mathbf{L}_{11} \mathbf{y}_{11}+\boldsymbol{\Phi}_{1}^{\mathbf{x}} \mathbf{L}_{12} \mathbf{y}_{21} & \boldsymbol{\Phi}_{1}^{\mathbf{x}} \mathbf{L}_{11} \mathbf{y}_{12}+\boldsymbol{\Phi}_{1}^{\mathbf{x}} \mathbf{L}_{12} \mathbf{y}_{22} \\
\boldsymbol{\Phi}_{2}^{\mathbf{x}} \mathbf{L}_{21} \mathbf{y}_{11}+\boldsymbol{\Phi}_{2}^{\mathbf{x}} \mathbf{L}_{22} \mathbf{y}_{21} & \boldsymbol{\Phi}_{2}^{\mathbf{x}} \mathbf{L}_{21} \mathbf{y}_{12}+\boldsymbol{\Phi}_{2}^{\mathbf{X}} \mathbf{L}_{22} \mathbf{y}_{22}
\end{array}\right)
\end{aligned}
$$

The first subscript on each element of Equation (2) identifies the producing region, $r$, and the second the consuming region, $s . \mathbf{L}_{\mathrm{rs}}$ is that sub-matrix of the partitioned Leontief inverse that gives the total impact on the output in the producing sectors on region $r$ per unit of final demand for output in region s. $f_{r s}^{x}$ is a scalar representing the amount of $\mathrm{CO}_{2}$ generated in production activities in region $r$ to support region $s$ final demand. Thus $\mathbf{f}_{11}^{\mathbf{x}}$ tells us the amount of $\mathrm{CO}_{2}$ that is used in production activities in region 1 to support final demand in region $1 . \mathbf{f}_{21}^{\mathbf{x}}$ is the amount of $\mathrm{CO}_{2}$ that is used in production activities in region 2 to support final demand in region 1 , and so on. 
Assuming that final consumers also directly generate $\mathrm{CO}_{2}$ emissions, these are incorporated with a $1 \times Z$ vector, $\boldsymbol{\Phi}_{r}^{y}$, of coefficients for each final consumption group $z$ in region $r$. Each element $\Phi_{z}^{r}$ describes the physical amount of $\mathrm{CO}_{2}$ that is directly generates per unit of final expenditure. Here, only one final consumption group, households (hh), generate direct emissions, so $z=h h=1$, and this emissions generation only takes place in the home region. So:

(3) $\left(\begin{array}{cc}f_{1}^{h h} & 0 \\ 0 & f_{2}^{h h}\end{array}\right)=\left(\begin{array}{cc}\Phi_{1}^{h h} & 0 \\ 0 & \Phi_{2}^{h h}\end{array}\right)\left(\begin{array}{cc}y_{1}^{h h} & 0 \\ 0 & y_{2}^{h h}\end{array}\right)$

By summing the partitioned matrices in Equations (2) and (3), McGregor et al. (2008) are able to measure all emissions in regions 1 and 2 that are attributable to final consumption demand in each region for the outputs of both regions. Total emissions generated in Scotland (region 1) are found by summing along the first row of each $\mathbf{f}$ matrix so that:

(4) $f_{1}^{x}=f_{11}^{x}+f_{12}^{x}+f_{1}^{h h}$

And total emissions in both regions of the UK that are attributable to Scottish (region 1) final consumption demand are found by summing down the first column of each $\mathbf{f}$ matrix so that:

(5) $f_{1}^{y}=f_{11}^{x}+f_{21}^{x}+f_{1}^{h h}$

In accordance with the Munksgaard and Pedersen's (2001) consumption accounting principle, Scotland's $\mathrm{CO}_{2}$ 'trade balance' with the RUK is calculated as the difference between Equations (4) and (5), and the corresponding calculations for RUK are carried out using the second row and column of the $\mathbf{f}$ matrices in (2) and (3). This means that the environmental 'trade balance' is given by: 
(6) $E T B=f_{r s}^{x}-f_{s r}^{x}$

In the framework outlined above, the treatment of interregional trade between Scotland and the RUK is in accordance with the consumption accounting principle, such that $\mathrm{CO}_{2}$ generation within the UK regions is attributed to consumption demand in the UK. However, since the UK is an open economy, the IO system of Equations (2) and (3) would need to be extended to incorporate foreign trade in order for the calculation to adhere to Munksgaard and Pedersen's (2001) consumption accounting principle (e.g. with the rest of the world, ROW, as a third region). In this analysis, for the sake of simplicity (and in the absence of an appropriate data set to adopt the consumption accounting principle for ROW trade), the system is closed by applying the production accounting principle to trade with the ROW. This means that emissions generated in Scotland that are attributable to ROW exports are assigned to Scotland's pollution account as part of Scottish final consumption demand, and similarly emissions generated in the RUK that are attributable to ROW exports are assigned to the RUK's pollution account. Moreover, pollution generated outside the UK but embodied in imports to Scottish and RUK imports from ROW is not considered. ${ }^{3}$ Thus Equations (2) and (3) do not fully represent Scottish or RUK emissions according to the consumption accounting principle.

\subsection{Scotland-RUK environmental IO accounting trade balance results}

A number of data problems were encountered in constructing the interregional IO and SAM framework used in this paper. These are explained in McGregor et al (2008) and are being addressed in our current programme of research (see Footnote 1). Nonetheless, while issues regarding the reliability of the data mean that the quantitative results of any analyses using the

\footnotetext{
${ }^{3}$ In McGregor et al's (2008) TELAS analysis, trade is endogenised so as to focus entirely on UK consumption regional demands, but the system is still closed under the production accounting principle at the national level. Other authors attempt a pollution attribution analysis fully under the consumption accounting principle, including estimation of pollution embodied in international trade (e.g. Druckman et al., 2008). See Wiedmann (2009) for a review.
} 
Scotland-RUK environmental IO and CGE models should be regarded as provisional, we believe that there is still merit in using the framework for an illustrative attribution analysis to examine the nature and level of interdependence between regions of the UK. In this paper we focus specifically on environmental spillover effects, the existence of a $\mathrm{CO} 2$ 'trade balance', and the impacts on key variables when a demand disturbance is introduced to the system. The Scotland-RUK models are used to provide a simple numerical example of the potential added value in moving from IO to CGE analysis where interest lies in examining the impacts of marginal changes in activity

Table 1 shows the results of calculating a final demand disaggregated version of equations (2)(6) for the conventional Type I case for the case of Scotland-RUK. Table 2 shows the 3 -sector disaggregation of production in each region (Manufacturing, Utilities and Services). Exogenous demands are given by regional Households, Government, Capital and exports to ROW (Scot$R O W$ and $R U K-R O W$ ) and all $\mathrm{CO} 2$ emissions generated in the UK allocated to these final demand categories in each region. It shows the scale of the CO2 "trade" (or "spillovers") that occur between Scotland and the rest of the UK. Of the total CO2 generated in the UK directly or indirectly as a result of conventional Scottish final demand expenditures, $25.6 \%$ is generated in RUK (i.e. not in Scotland). A slightly smaller proportion, $24.9 \%$, of $\mathrm{CO} 2$ generated in Scotland is to support, directly or indirectly, RUK final demand. Also note that Scottish exports to the rest of the world, which produce no direct CO2 outwith Scotland, still generate sizeable amounts (2.6 million tonnes) of $\mathrm{CO} 2$ in the RUK as a result of the indirect impacts of the production of intermediate inputs, and similarly for the impact of RUK exports to the ROW in terms of $\mathrm{CO} 2$ emissions in Scotland (1.8 million tonnes).

\section{Insert Tables 1 and 2 around here}

There is a very small (-0.4 million tonnes) negative $\mathrm{CO} 2$ trade balance for Scotland, reflecting the result that the pollution generated in Scotland by production to support RUK final demands 
(12.2 million tonnes) is less than the pollution generated in the RUK by production supporting Scottish final demands (12.6 million tonnes). Note, however, that the precise levels and proportions of emissions attributable to different activities, and the size of the $\mathrm{CO} 2$ trade balance in Table 1 are dependent on the Type I assumption employed here. See McGregor et al (2008) for the impacts of adopting different assumptions (Type I against TELAS, with trade endogenised) in the same framework. For example, in the TELAS case, McGregor et al (2008) find that Scotland's $\mathrm{CO} 2$ trade deficit becomes a surplus, due to Scotland being a net exporter to the ROW (in the year of 1999 that the accounts relate to), while the RUK region is a net importer. ${ }^{4}$

The analysis above is an accounting exercise, where we attribute $\mathrm{CO} 2$ emissions generated in the UK in the year to which our accounts relate (1999) to different elements of final demand for UK production. Here the elements of the A-matrix are taken to represent average input requirements in 1999, and the multipliers given by the Leontief inverse matrix tell us, on average, what levels of activity, including pollution generation, were supported by different types of final demand during this time period. Using (Type I) IO demand-driven multipliers in this way is absolutely appropriate because they give all the required information on pollution embodied in intersectoral interactions and interregional trade flows.

However, if we want to consider how the economy moves from one equilibrium to another in response to a marginal change in activity, it is inappropriate to use the demand driven IO system because this is only a very special case of a wider set of general equilibrium models, involving rather restrictive assumptions regarding the supply-side of the economy. Therefore, we propose that, where marginal impact analyses are required, a non-IO modelling approach be adopted.

\footnotetext{
${ }^{4}$ McGregor et al's (2008) TELAS analys is involves endogenising regional trade with ROW by moving exports and imports to and from ROW from the $\mathbf{y}$ into the A matrix - exports become the inputs to a regional 'Trade' sector where the output is total imports to the region from ROW. Thus, the elements of the additional column for each region are given by each sector's exports to ROW divided by total regional imports from ROW, and the elements of the additional row for each region are given by each sector's imports from ROW divided by its total input requirement. The final demand vector $\mathbf{y}$ is extended with direct imports to local exogenous final consumers (households, government and capital formation).
} 
Specifically, more flexible computable general equilibrium (CGE) analyses can be used to augment the information set provided by the IO accounting framework. In the next section we introduce our AMOSUK model, which uses the IO account from above as its core database, but adds information on transfer payments, unemployment and social benefits in a social accounting matrix (SAM). We use this model to simulate the impacts of a simple illustrative demand shock on the $\mathrm{CO} 2$ trade balance between Scotland and RUK.

\section{CGE analysis of the change in the CO2 trade balance between Scotland and RUK in response to an increase in export demand in RUK}

\subsection{An illustrative CGE model: the AMOSRUK interregional model of Scotland and the rest of the UK}

Full details of the AMOSRUK modelling framework in this paper are given in the model summary in Appendix 1 and also in Gilmartin et al (2008). ${ }^{5}$ Here, we summarise the main features of the CGE model that add value when analysing the impacts of the marginal change in activity as compared to the conventional demand driven IO approach. These are as follows:

- A degree of substitutability, in response to changes in relative prices, is introduced in both production and final consumption decisions.

- International export demand is price sensitive. Interregional export demand is fully endogenous depending not only on relative prices, but also on the structure of all elements of intermediate and final demand in the other region.

\footnotetext{
${ }^{5}$ Harrigan et al (1991) gives a full description of early versions of the AMOS framework, and McGregor et al (1999) and Gillespie et al (2002) describe the interregional model AMOSRUK. Greenaway et al (1993) provides a general appraisal of CGE models and Partridge and Rickman (1998, 2008) review regional CGEs.
} 
- Household income and expenditures are endogenous (this would be possible in a Type II IO modelling analysis, but, as well as the more general limitations of IO in a modelling context, with income limited to wages and with the loss of household consumption as an exogenous driver of economic activity and pollution generation).

- The model is dynamic with primary factor stocks, capital and labour, updated endogenously between periods.

- In each period (year) investment demand in each sector is set equal to depreciation plus a proportion of the difference between actual and desired capital stock. In response to a shock, investment optimally adjusts capital stocks, gradually relaxing any capacity constraints. The labour force can also be updated following a shock. In the current application we assume that there is no natural population increase and no international migration. However, in one of the simulations reported below, regional labour forces are adjusted through interregional migration.

\subsection{Simulation strategy}

The analysis reported in this section considers the system-wide effects on Scotland and the RUK of a $10 \%$ increase in ROW export demand for the outputs of the RUK Manufacturing sector (see Table 2 above for sectoral classifications) under different wage-setting and migration assumptions, each of which reflects a commonly-encountered view of how regional labour markets operate in the regional macroeconomic and labour market literature (see Gilmartin et al, 2008). We refer to these as:

- Quasi IO - real wages and population fixed at their initial levels. This is effectively an extended Type II IO framework that endogenises investment, transfer payments and unemployment and social benefits; 
- Regional Wage Bargaining (with no migration) - where real wages are determined via a conventional regional 'wage curve', with wages inversely related to the unemployment rate, and regional population fixed at the initial level (with the bargaining function taken from UK regional econometric work by Layard et al, 1991);

- Regional Wage Bargaining with Flow Migration - with regional wage determination as in the previous case but with population fixed only at the national level. Interregional migration is determined by changes in relative real wage and unemployment rates in Scotland and RUK (based on the model of Harris and Todaro, 1970, with real wage and unemployment differentials based on the UK regional econometric work of Layard, et al, 1991).

\section{Insert Table 3 around here}

These labour market configurations are summarised in Table 3 (fuller details are given in Gilmartin et al, 2008). One of the advantages gained in moving to a CGE framework for the modelling component of our analysis is that we can consider reactions to changes in prices and supply constraints. In the three scenarios we consider (a) the major source of prices changes stemming from the labour market - that is variation in real wages - and (b) the main constraint on labour as a factor of production - that is whether the labour supply in each region can adjust through interregional migration.

We label the first scenario Quasi IO because it is closest to a (Type II) IO modelling framework with the real wage fixed (Batey and Madden, 1998). Increased employment is met by increased regional labour market participation, but with no change in real wages. Neither region suffers adverse competitiveness effects generated specifically through the labour market as export demand expands. The nominal wage changes but only in response to changes in the regional consumer price index (CPI). Capital fixity dictates supply restrictions, so that marginal costs and prices rise in the short run as output expands. Over time, however, investment optimally 
adjusts capital stocks, relaxing capacity constraints so that, for a demand shock, the economy ultimately operates like an extended conventional IO system (McGregor et al, 1996). In the other two scenarios, we move further away from the IO case. In the Regional Wage Bargaining scenario (with no migration - summarised as Bargaining in the charts below) the regional wage varies in response to changes in labour demand. In the Regional Wage Bargaining with Flow Migration (summarised as Flow Migraiton), flow migration in response to changes in regional real wage and unemployment rates is added to this, allowing both real wages and regional population to vary in response to the demand shock. Again, in both cases, over time investment allows capacity adjustments across regions and sectors.

Under each scenario the increase in export demand is introduced as a permanent step increase in period 1 and the model is run forward for 75 periods (years). ${ }^{6}$ The values of all other exogenous variables are held constant, and the changes from the initial base-period value are reported for the key variables. Crucially, though, all export demands are also determined endogenously and respond to the relative price changes that occur in response to the initial exogenous demand shock. In all cases, investment is endogenous and sectoral capital stocks are updated between periods. Also, as noted above, under the Flow Migration configuration the regional populations are adjusted in response to relative changes in the regional labour markets, but remain constant in the other two labour market closures.

The model calibration process takes the economy to be initially in long-run equilibrium, so that if the model is run forward with unchanged exogenous variables and parameters, the endogenous variables continuously take their initial values. Introducing a step change drives the economy towards a new long-run equilibrium and it is the paths to the new, comparative static, equilibria that are reported here. The different model configurations generate both different long run equilibria and different adjustment paths.

\footnotetext{
${ }^{6}$ Note that it is possible to introduce disturbances (on the supply or demand side) more gradually to the CGE model, and shocks may be permanent or transitory.
} 
In each simulation, we run the model period-by-period (year-by-year) and use the results to create a new interregional IO table (incorporating the impacts of the demand shock) in each period and use this to account for the environmental $(\mathrm{CO} 2)$ trade balance between Scotland and the Rest of the UK using Equations (2) - (6) above.

\subsection{Simulation results}

If a positive demand shock, such as the $10 \%$ ROW export demand stimulus to the RUK Manufacturing sector here, were introduced to a conventional demand driven IO model, we would expect to observe not only boosted economic activity in RUK, as the region directly targeted with the shock, but also in Scotland (see Gilmartin et al, 2008, for a full analysis of this shock in the IO model). The boost to Scotland would be indirect, driven by the need for RUK sectors to import intermediate inputs required to meet the increase in demand from Scotland. With no supply constraints, activity in both regions would increase with no changes in prices so that there would be no negative competitiveness effects and, thus, the full initial increase in RUK export demand would be reflected in the new equilibrium.

In terms of the $\mathrm{CO} 2$ trade balance between Scotland and RUK, only the elements where the stimulus in exogenous final demand has taken place will change. These are Scottish and RUK emissions supported by RUK final demand from ROW (highlighted in bold font in the initial CO2 trade balance results in Table 1). $\mathrm{CO} 2$ generation in the UK regions attributable to household and government final consumption, and to capital formation will remain unchanged.

However, in the CGE simulations here, even in the Quasi IO case, where the model is configured to resemble a conventional demand driven IO model, it takes time to adjust for both 
the RUK and Scottish economies to fully adjust to the shock. In the short run capital stocks are fixed, as is population in each region, with the implication that there is not sufficient capacity in the system to meet the increase in demand at the outset. In all three labour market scenarios identified above, capital stocks gradually update through investment, but the adjustment (or not) of regional labour supplies varies, as does the treatment of labour costs. However, in all three scenarios, there is an increase in total factor costs in the region directly targeted with the shock (RUK), at least through increased capital rental rates. This puts upward pressure on production costs and the price of output in all three RUK production sectors (not just the sector directly targeted with the shock). As a result there are negative competitiveness effects so that the initial increase in ROW export demand to the RUK Manufacturing sector is not fully realised from the outset, and ROW export demand actually initially falls in the other RUK production sectors. This is because ROW export demand responds to changes in the price of outputs.

The impacts of short-run supply constraints in both regions are summarised in Figure 1, where we show the response of output production in each production sector in each region to the $10 \%$ increase in ROW export demand to the RUK Manufacturing sector. Note that in the Quasi IO case activity across the two regions adjusts to a higher level than would be predicted by a conventional Type I or Type II IO model. This is for two reasons. First, a Type I IO model does not take account of induced income and consumption effects in the household sector. Second, even if such effects were incorporated in a Type II IO model, the CGE model uses a social accounting matrix database that includes income transfers not considered in an IO model, making multiplier effects larger.

Insert Figure 1 around here 
However, Figure 1 shows that the growth in activity is more limited in both the Regional Wage Bargaining cases (with or without flow migration), as compared to the Quasi IO case. Where the national population constraint is coupled with flexible real wages, there are lasting negative competitiveness effects, which lead to a permanent crowding out of exports in the two sectors that do not directly benefit from exogenous increase in ROW export demand. Moreover, the full $10 \%$ increase is never actually achieved in the targeted sector. Only under the Quasi IO closure, where there is no change in real wages is the impact of the national labour supply constraint mitigated so that the full value of the exogenous demand shock is realised. This translates to a long run increase in GDP of just under $2.8 \%$.

However, the Quasi IO closure is mainly of interest as dynamic transition to what we would expect under a fixed price IO model. In the UK economy, we would expect to observe regional price effects, particularly real wage effects. Under Flow Migration the increase in the real wage is mitigated to some extent by interregional migration from Scotland to RUK (relative to Bargaining, where the regional population is fixed also). Thus, the long-run output and GDP effects in the target region are much more muted than in the Quasi IO case, with a more limited $0.8 \%$ increase in GDP under Flow migration.

However, the migration of labour to RUK (the region directly targeted with the shock) from Scotland is one of several factors impacting on activity in that region. First, common to all scenarios is the fact that, while Scotland is not directly impacted by the ROW export demand shock, there is a positive demand stimulus due to the fact that RUK production sectors need to import intermediate imports from Scotland. However, Scotland also imports from RUK, with the implication that over the shorter run under all three labour market closures there is also a negative supply shock in Scotland as a result of rising prices in RUK. Moreover, the indirect demand stimulus also puts upward pressure on capital rental rates and real wages (except in the Quasi IO case) in Scotland as well. Under all three labour market scenarios the presence of an 
active supply-side means that in both regions the effects of the disturbance are both supply and demand orientated in the Scottish economy. However, if we compare the RUK and Scottish sectoral output results in Figure 1, we see that, while it is under the Bargaining scenario that we observe the smallest boost to RUK outputs, it is under the Flow Migration scenario that Scottish activity levels performs worse. Indeed in the Flow Migration case, activity in all three Scottish production sectors actually falls over time. This is because interregional migration acts to introduce an additional supply constraint in the Scottish regional economy.

As explained above, the Flow Migration scenario involves relaxing the regional population constraint and allowing interregional migration between Scotland and RUK in response to changes in relative real wage rates and unemployment in the two regions. While migration to the RUK in response to increased real wage wages reduces the tightness in the RUK labour market that results from the direct demand stimulus, it has the opposite effect in Scotland, introducing an additional supply constraint and counteracting the indirect demand stimulus to Scotland. This leads to a long-run contraction in Scottish GDP (of $0.86 \%$ ) over the long run.

In order to examine the impact of the demand stimulus on $\mathrm{CO} 2$ generation and the $\mathrm{CO} 2$ trade balance, the CGE results are used to generate a post-shock interregional IO table for the longrun equilibrium under each labour market closure. From this, a new interregional $\mathbf{A}$ matrix and final demand sub-vectors $\mathbf{y}$ are derived for each case to allow estimation of equations (2) to (6) reflecting the new long-run equilibrium in the Scottish and RUK economies. The differences between the aggregate Type I attribution results for this new long-run equilibrium and the initial (pre-shock) equilibrium in Table 1 are reported in Table 4, and in detail for the Flow migration case in Table 5 (where the post-shock $\mathrm{CO} 2$ trade balance results are also reported in physical units). 
A key result in terms of interregional trade flows and the $\mathrm{CO} 2$ trade balance between Scotland and RUK is that the short-run increase in RUK prices causes Scottish producers and consumers reduce imports from RUK under all three labour market closures. However, where we have flexible real wages, the negative impact lasts into the long run. This is reflected in Table 4, where RUK CO2 generation to support Scottish consumption demand falls over the long run under both the Bargaining scenario (-1.43\%) and under Flow Migration (-1.59\%). Under Quasi $\mathrm{IO}$, where there is no lasting impact on prices, $\mathrm{CO} 2$ generation rises in both regions over the long-run, with an increase in interregional trade flows and $\mathrm{CO} 2$ embodied therein. However, given the direct demand stimulus to RUK and consequently the greater increase in activity in this region, $\mathrm{CO} 2$ embodied in imports to RUK from Scotland rises by more (3.04\%) than the $\mathrm{CO} 2$ embodied in trade flows in the opposite direction $(0.6 \%)$. This leads to a significant longrun decrease (-69.8\%) in the size of Scotland's CO2 trade deficit with RUK.

A larger decrease in this deficit (-91.2\%) is observed in the case of the Bargaining scenario where, as discussed above, the expansion in RUK activity is most limited. Here, the larger decrease in Scotland's CO2 trade surplus is caused by a smaller increase in Scottish CO2 generation supported by the more limited expansion in RUK consumption activity but also a decrease $(-1.43 \%)$ in RUK CO2 generation supported by Scottish demand. This is due to the fact that the lasting increase in RUK prices causes the underlying trade flow (Scottish imports from RUK) to decrease in the new long-run equilibrium.

In the case of Flow Migration, while the decrease in Scotland's CO2 trade deficit with RUK ($69.1 \%$ ) is similar in magnitude to that under the Quasi IO closure (-69.8\%), Table 5 shows that the change in the underlying trade patterns is quite different. While under Quasi IO interregional 
trade is boosted in both directions (along with the overall increase in activity in both regions), under Flow Migration (where movement of labour supply from Scotland to RUK causes a lasting supply constraint in Scotland) there is a much smaller increase in Scottish exports to and a decrease in Scottish imports from RUK. Reflecting the overall contraction in activity in Scotland, CO2 generation in this region falls (by 0.65\%) with a smaller increase in Scottish CO2 supported by RUK demand (0.75\%) than under either Quasi IO (3.04\%) or Bargaining (1.69\%) and a decrease in RUK CO2 generation supported by Scottish demand (-1.59\%).

Insert Table 5 around here

Table 5 provides more detail on the change in the $\mathrm{CO} 2$ trade balance under the Flow Migration Scenario. Here the decrease in RUK exports to Scotland (due to the increase in RUK prices and contraction in Scottish activity) is reflected in the reduction in RUK emissions supported by each and every type of Scottish final demand. Scottish exports to RUK, on the other hand, rise from the outset to meet increased intermediate and final consumption demand as the RUK economy expands. As a result, Scottish emissions supported by RUK final demand also rise. However, Table 5 shows that this is partly due to increased $\mathrm{CO} 2$ generation to meet RUK household demand but mainly due to the increase in ROW demand for RUK production. Scottish $\mathrm{CO} 2$ generation supported by RUK capital and government final consumption demands actually falls due to crowding out effects in the presence of the national labour supply constraint.

Moreover, while it is not shown in Table 5, it is also important to note that the composition of interregional trade flows also changes. This is due to the exogenous demand stimulus being focussed in the RUK Primary, Manufacturing and construction sector, with the corresponding 
Scottish sector receiving the largest immediate demand stimulus from RUK (1.58\% in year 1 under Flow Migration). The Scottish Electricity, Gas and Water Supply sector receives the smallest increase in RUK export demand in period $1(0.67 \%)$. However, given the relative CO2intensity of this sector, emissions generation to support RUK demand rises more than proportionately $(1.1 \%)$. However, the growth in Scottish exports to ROW declines over time under Flow Migration, in line with the more limited growth in activity more generally as the labour market tightens due to the out migration of labour to RUK.

Generally, Table 5 shows that, over the long run (under Flow Migration) there is a decline in CO2 emissions supported by all types of activity except RUK household and capital formation demands, along with the ROW export demand for RUK production that are directly stimulated. This is due to the general crowding out of activities not directly targeted with the demand stimulus in both Scotland and RUK in the presence of the national population constraint. In Scotland, this nets out to a long-run decrease in economy-wide $\mathrm{CO} 2$ emissions of $0.65 \%$. In RUK, on the other hand there is a net increase of $1.31 \%$. At the national UK level there is a net increase in $\mathrm{CO} 2$ emissions of $1.14 \%$. In terms of the $\mathrm{CO} 2$ trade balance, the net growth in Scottish emissions supported by RUK final demands (specifically ROW demand for RUK production) and decrease in RUK emissions supported by Scottish final demands (including ROW demands, given the loss in Scottish competitiveness) nets out to a large reduction in the size of Scotland's CO2 'trade deficit' with RUK (from 0.4 to 0.13 million tonnes).

A final point to note is that the added value from the CGE analysis is captured in the fact that there are changes throughout Table 5. In an IO modelling analysis only emissions in Scotland and RUK supported by ROW export demands for RUK outputs (highlighted in bold font in Table 5) would adjust. This reflects the fact that both prices and quantities are determined endogenously in the CGE framework, and that the former also change due to the presence of an active supply side (note that the equivalent of Table 5 in the Quasi IO case would show wider 
changes than the IO modelling case due to the imposition of a national labour supply constraint in the CGE analyses here). This in turn induces further changes in local intermediate and final demands, as well as export demand for production in both regions, and both elements of Scotland's CO2 trade balance (emissions embodied in interregional exports and imports to and from RUK) change.

\section{Summary and conclusions}

There is currently a great deal of interest at the national and regional levels in the UK, and internationally, in accounting for carbon emissions using consumption based measures, such as carbon footprints. In this paper we argue that, while IO is a powerful accounting tool in this respect, if there is a need to model the impacts of marginal changes in activity, IO is only one very special case of multi-sectoral general equilibrium modelling. In particular, it is limited due to its assumption of a passive supply-side and silence on prices. Therefore, we propose that interregional environmental IO frameworks should be used for accounting applications (as is increasingly the case), but, if interest lies in assessing the likely impacts of changes in economic activity, that they be complemented with a more flexible CGE modelling framework. This involves using the IO tables as the core of the SAM database, with the result that the information content and, thus, the benefits of using a multi-sectoral, system-wide framework are not lost. What the CGE approach for modelling the impacts of changes in activity offers is more theory-consistent modelling of both supply and demand-side behaviour and a fuller account of how the economy responds and adjusts to demand- and/or supply-side disturbances. However, we argue that it is appropriate to revert to the IO accounting framework (with post-shock IO tables derived from CGE results) to analyse the structure of pollution generation after a change in activity has been modelled outside of the IO. 
We close by emphasising that our numerical results must be qualified on three counts. First, the demand shock introduced is somewhat blunt and unrealistic. CGE models can be used both for more focussed policy analysis (of both supply and demand side disturbances or policy instruments) and to compare results under different theoretical perspectives (as we have done here by configuring our model to represent different stylised versions of labour market configurations that are common in the labour market and regional macroeconomic literature). Second, as explained in McGregor et al (2008), our interregional IO and SAM data for the UK incorporate estimated and experimental data that may distort model results. Third, the 3 -sector, 2-region national framework is likely to be too highly sectorally (and perhaps spatially) aggregated for analysis of environmental issues. However, we would argue that sectoral disaggregation is not the key issue in the added value offered by moving to a CGE framework for impact analyses. Nonetheless, we are currently in the process of addressing all of these issues in our ongoing programme of research in this area (where we are also developing interregional applications for the US and hope to also to attempt to examine international trade flow issues).

\section{References}

Allan, G.J., Hanley, N.D., McGregor, P.G., Swales, J.K. and Turner, K.R. 2007. The impact of increased efficiency in the industrial use of energy: a computable general equilibrium analysis for the United Kingdom. Energy Economics. 29: 779-798.

Allan, G., Hanley, N.D., McGregor, P.G., Swales, J.K. and Turner, K.R. 2007b. Augmenting the Input-Output Framework for "Common Pool" Resources: Operationalising the Full Leontief Environmental Model. Economic Systems Research, 19: 1-20. 
Anson, S. and Turner, K. 2009. Rebound and disinvestment effects in refined oil consumption and supply resulting from an increase in energy efficiency in the Scottish commercial transport sector. Energy Policy, 37: 3608-3620.

Batey, P. and Madden, M. 1998. The treatment of migration in an extended input-output modelling framework. Ricerche Economische, 42: 344-366.

Beauséjour L, Lenjosek G, Smart M. 1995. A CGE Approach to Modelling Carbon Dioxide Emissions Control in Canada and the United States. The World Economy, 18: 457-489.

Conrad K. 1999. Computable General Equilibrium Models for Environmental Economics and Policy Analysis. In: van den Bergh JCJM (Editor), Handbook of Environmental and Resource Economics. Edward Elgar Publishing Ltd, Cheltenham.

Druckman, A., Bradley, P., Papthanasopoulou, E., and Jackson, T. (2008) 'Measuring progress towards carbon reduction in the UK', Ecological Economics, Vol. 66: 594-604.

Gillespie G. McGregor, P.G. Swales, J.K. and Yin, Y.P. 2002. A Computable General Equilibrium Approach to the Ex Post Evaluation of Regional Development Agency Policies. In: B. Johansson, C. Karlsson and R. Slough (Editors), Regional Policies and Comparative Advantage. Edward Elgar Publishing Ltd, Cheltenham, pp. 253-282.

Gilmartin, M., Learmonth, D., McGregor, P.G., Swales, J.K. and Turner, K. 2007a. The national impact of regional policy: demand-side policy simulation with labour market constraints in a two-region computable general equilibrium analysis. Strathclyde Discussion Papers in Economics: 07-04. 
Gilmartin, M., McGregor, P.G. and Swales, J.K. 2007b. The national impact of regional policy: supply-side policy simulation with labour market constraints in a two-region computable general equilibrium analysis. Strathclyde Discussion Papers in Economics: 07-05.

Gilmartin, M., Swales, J.K. and Turner, K. 2008. A comparison of results from MRIO and interregional computable general equilibrium (CGE) analyses of the impacts of a positive demand shock on the 'CO2 trade balance' between Scotland and the rest of the UK. Strathclyde Discussion Papers in Economics: 08-08.

Greenaway, D., Leyborne, S. Reed, G. and Whalley, J. 1993. Applied General Equilibrium Modelling: Applications, Limitations and Future Developments. HMSO, London.

Ha, S.J., Hewings, G. and Turner, K. 2009. An interregional input-output analysis of the pollution content of trade flow and environmental trade balances between five states in the US Midwest. Strathclyde Discussion Papers in Economics: 09-20.

Hanley N.D., McGregor P.G., Swales J.K., Turner K.R. 2006. The impact of a stimulus to energy efficiency on the economy and the environment: A regional computable general equilibrium analysis. Renewable Energy, 31: 161-171.

Hanley ND, McGregor PG, Swales JK, Turner KR. 2009. Do increases in energy efficiency improve environmental quality and sustainability?, Ecological Economics, 68, pp.692-709.

Harrigan, F., P.G. McGregor, N. Dournashkin, R. Perman, J.K. Swales and Y.P. Yin 1991. AMOS: A Macro-Micro Model of Scotland. Economic Modelling, 10; 424-479.

Harris, J.R. and Todaro, M. 1970. Migration, Unemployment and Development: A Two-Sector Analysis, American Economic Review, 60; 126-42. 
Hertel, T. (Editor), 1997. Global trade analysis: modelling and applications. Cambridge University Press.

Layard, R., Nickell, S. and Jackman, R. 1991. Unemployment: Macroeconomic Performance and the Labour Market, Oxford University Press, Oxford.

McGregor, P.G., J.K. Swales and Yin, Y.P. 1996. A Long-Run Interpretation of Regional InputOutput Analysis. Journal of Regional Science, 36: 479-501.

McGregor, P.G. Swales, J.K. and Yin, Y.P. 1999. Spillover and Feedback Effects in General Equilibrium Models of the National Economy: A Requiem for Inter-Regional Input-Output? In G. Hewings, M. Sonis, M. Madden and Y, Koimura (Editors), Understanding and Interpreting Economic Structure. Berlin, pp.167-190.

McGregor, P.G., Swales, J.K. and Turner, K. (2008). The CO2 trade balance between Scotland and the rest of the UK: performing a multi-regional environmental input-output analysis with limited data. Ecological Economics, 66: 662-673.

Miller, R.E. and Blair P.D. 1985. Input-Output Analysis: Foundations and Extensions. PrenticeHall.

Miller, R.E. and Blair P.D. 2009. Input-Output Analysis: Foundations and Extensions. Cambridge University Press.

Munksgaard, J. and Pedersen, K.A. 2001. CO2 accounts for open economies: producer or consumer responsibility? Energy Policy, 29: 327-334. 
Partridge, M. and Rickman, D. 1998. Regional Computable General Equilibrium Modelling: A Survey and Critical Appraisal. International Regional Science Review, 21: 205-248.

Partridge, M. and Rickman, D. 2008. CGE Modelling for Regional Economic Development Analysis, Regional Studies, forthcoming.

Turner, K. 2009. Negative rebound and disinvestment effects in response to an improvement in energy efficiency in the UK Economy, Energy Economics, 31: 648-666.

Turner, K., Lenzen, M., Wiedmann, T. and Barrett, J. 2007. Examining the Global Environmental Impact of Regional Consumption Activities - Part 1: A Technical Note on Combining Input-Output and Ecological Footprint Analysis. Ecological Economics, 62: 37-44.

Welsch, H. 1996. Recycling of carbon/energy taxes and the labour market: a general equilibrium analysis for the European Community. Environmental and Resource Economics, 8: 141-155.

Wiedmann, T. 2009. A review of recent multi-region input-output models used for consumption based emission and resource accounting. Ecological Economics, 69: 211-222.

Wiedmann, T. Lenzen, M., Barrett, J. and Turner, K. 2007. Examining the Global Environmental Impact of Regional Consumption Activities Part 2: Review of input-output models for the assessment of environmental impacts embodied in trade. Ecological Economics, 61: 15-26.

Wissema, W. and Dellink, R. 2007 A CGE analysis of the impact of a carbon energy tax on the Irish economy. Ecological Economics, 61: 671-683. 


\section{Appendix 1. AMOSRUK Condensed Model Listing}

\begin{tabular}{|c|c|c|}
\hline Value-added prices & $p v_{i}^{x}=p v_{i}^{x}\left(w_{n}^{x}, w_{k}^{x}\right)$ & (A.1) \\
\hline Commodity prices & $p_{i}^{x}=p_{i}^{x}\left(p v_{i}^{x}, \underline{p}_{j-i}^{x}, \underline{p}^{y}, \underline{p}^{w}\right)$ & (A.2) \\
\hline Consumer price index & $c p i^{x}=\sum_{i} \theta_{i}^{x x} p_{i}^{x}+\sum_{i} \theta_{i}^{x y} p_{i}^{y}+\sum_{i} \theta_{i}^{x w} \bar{p}_{i}^{w}$ & (A.3) \\
\hline Capital price index & $k p i^{x}=\sum_{i} \gamma_{i}^{x x} p_{i}^{x}+\sum_{i} \gamma_{i}^{x y} p_{i}^{y}+\sum_{i} \gamma_{i}^{x w} \bar{p}_{i}^{w}$ & (A.4) \\
\hline Labour demand & $N_{i}^{x}=N_{i}^{x}\left(Q_{i}^{x}, p_{i}^{x}, p v_{i}^{x}, w_{n}^{x}\right)$ & (A.5) \\
\hline Capital demand & $K_{i}^{x}=K_{i}^{x}\left(Q_{i}^{x}, p_{i}^{x}, p v_{i}^{x}, w_{k}^{x}\right)$ & (A.6) \\
\hline Capital rental rate & $K_{i}^{x}=K_{i}^{s x}$ & (A.7) \\
\hline Household income & $Y^{x}=\varphi_{n}^{x} N^{x} w_{n}^{x}+\varphi_{k}^{x} K^{x} w_{k}^{x}+L^{x} T^{x} u^{x} f$ & (A.8) \\
\hline Commodity demands & $Q_{i}^{x}=C_{i}^{x}+J_{i}^{x}+I_{i}^{x}+G_{i}^{x}+X_{i}^{x y}+X_{i}^{x w}$ & (A.9) \\
\hline Consumption demand & $C_{i}^{x}=C_{i}^{x}\left(\underline{p}^{x}, \underline{p}^{y}, \underline{p}^{w}, Y^{x}\right)$ & (A.10) \\
\hline Intermediate demand & $J_{i}^{x}=J_{i}^{x}\left(\underline{Q}^{x}, \underline{p v}{ }^{x}, \underline{p}^{x}, \underline{p}^{y}, \underline{p}^{w}\right)$ & $(\mathrm{A} .11)$ \\
\hline Investment demand & $I_{i}^{x}=I_{i}^{x}\left(\underline{p}^{x}, \underline{p}^{y}, \underline{\bar{p}}^{w}, \sum_{j} b_{i j}^{x} \Delta K_{j}^{x}\right)$ & (A.12) \\
\hline Government demand & $G_{i}^{x}=\alpha_{i}^{x} \bar{G}^{N}$ & (A.13) \\
\hline $\begin{array}{l}\text { Interregional export } \\
\text { demand }\end{array}$ & $X_{i}^{x y}=X_{i}^{x y}\left(\underline{p}^{x}, \underline{p}^{y}, \underline{p}^{w}, \bar{G}^{N}, \underline{J}^{y}, \underline{Q}^{y}, Y^{y}\right)$ & (A.14) \\
\hline $\begin{array}{l}\text { International export } \\
\text { demand }\end{array}$ & $X_{i}^{x w}=X_{i}^{x w}\left(\underline{p}^{x}, \underline{p}^{w}, \bar{D}^{w}\right)$ & (A.15) \\
\hline Capital stock & $K_{i, t}^{s x}=\left(1-\delta_{i}^{x}\right) K_{i, t-1}^{s x}+\Delta K_{i, t-1}^{x}$ & (A.16) \\
\hline Desired capital stock & $K_{i, t}^{*_{s x}}=K_{i, t}^{* s x}\left(Q_{i}^{x}, p_{i}^{x}, p v_{i}^{x}, u c c^{x}\right)$ & (A.17) \\
\hline User cost of capital & $u c c^{x}=u c c^{x}\left(k p i^{x}\right)$ & (A.18) \\
\hline Investment & $\Delta K_{i, t}^{x}=\lambda\left(K_{i, t}^{* s x}-K_{i, t}^{s x}\right)+\delta_{i}^{x} K_{i, t-1}^{s x}$ & (A.19) \\
\hline National population & $\bar{L}^{N}=L^{s}+L^{r}$ & (A.20) \\
\hline
\end{tabular}




\begin{tabular}{|l|c|l|}
\hline Regional population & $L_{t}^{s}=L_{t-1}^{s}+m_{t-1}^{s}$ & (A.21) \\
\hline Migration & $m_{t}^{s}=m^{s}\left[\frac{w_{t}^{s}}{c p i_{t}^{s}}, \frac{w_{t}^{r}}{c p i_{t}^{r}}, u_{t}^{s}, u_{t}^{r}, L_{t}^{s}\right]$ & (A.22) \\
\hline Unemployment rate & $u^{x}=\frac{L^{x} T^{x}-\sum_{i} N_{i}^{x}}{L^{x} T^{x}}$ & (A.23) \\
\hline Bargaining & $w_{n}^{x}=w_{n}^{x}\left(u^{x}, c p i^{x}\right)$ & (A.24) \\
\hline Quasi IO & $w_{n}^{s}=\beta^{x} c p i^{x}$ & (A.25) \\
\hline Wage Spillover & $w_{n}^{x}=w_{n}^{y}$ & (A.26) \\
\hline
\end{tabular}

Endogenous variables:

cpi : consumer price index

$k p i$ : capital price index

$m$ : Scottish immigration

$p$ : commodity price

$p v$ : value-added price

$u$ : unemployment rate

ucc : user cost of capital

$w_{n}$ : nominal wage rate

$w_{k}$ : capital rental rate

$C$ : consumption

$D$ : foreign demand

$G$ : government expenditure

$I$ : investment demand

$J$ : intermediate demand

$K$ : capital demand

$K^{s}$ : capital supply

$\Delta K$ : capital stock adjustment

$L$ : population

$N$ : employment

$Q$ : output 
$X$ : exports

$Y$ : household income

Parameters and exogenous variables:

$b$ : capital coefficient

$f$ : benefit payment per registered unemployed

$D$ : rest of the world demand

$T$ : participation rate

$\alpha$ : government expenditure coefficient

$\beta$ : real wage coefficient

$\delta$ : depreciation rate

$\varphi$ : regional share of factor income

$\theta$ : consumption expenditure share

$\gamma$ : capital expenditure share

$\lambda$ : capital stock adjustment parameter

Subscripts:

$i, j$ : sectors

$k$ : capital

$n$ : labour

$t$ : time

Superscripts:

$r$ : rest of the UK

$s$ : Scotland

$w$ : rest of the world

$x, y$ : generic regional identifiers

\section{Functions:}

$m($.$) : migration function$

$p(),. p v($.$) : cost function$

$u c c($.$) : user cost of capital function$ 
$w($.$) : wage curve$

$C($.$) : Armington consumption demand function$

I(.): Armington investment demand function

$J($.$) : Armington intermediate demand function$

$K(),. N($.$) : factor demand functions$

$X($.$) : Armington export demand function$

Notes:

- A bar above a variable indicates that this variable is exogenous for the purposes of the simulations) i.e. a bar over a variable denotes exogeneity.

- Underlined variables are vectors whose elements are the sectoral values of the corresponding variables. Where the subscript $j-i$ is used, this represents a vector of all sectoral values, excluding sector $i$.

- A starred variable indicates desired value.

Implicit time subscripts apply to all the variables, and these are stated explicitly only for the relevant updating equations (Equations A.1 to A.10). 


\section{Tables}

Table 1. The CO2 Trade Balance Between Scotland and RUK (tonnes, millions) - Type I Input-Output

\begin{tabular}{|c|c|c|c|c|c|c|c|c|c|}
\hline & \multicolumn{8}{|c|}{ Pollution supported by: } & \multirow{2}{*}{$\begin{array}{l}\text { Total regional } \\
\text { emissions of } \\
\mathrm{CO} 2\end{array}$} \\
\hline & $\begin{array}{c}\text { Scottish } \\
\text { HH }\end{array}$ & $\begin{array}{c}\text { Scottish } \\
\text { Govt }\end{array}$ & $\begin{array}{r}\text { Scottish } \\
\text { Capital }\end{array}$ & $\begin{array}{l}\text { Scot- } \\
\text { ROW }\end{array}$ & $\begin{array}{c}\text { RUK } \\
\text { HH }\end{array}$ & $\begin{array}{l}\text { RUK } \\
\text { Govt }\end{array}$ & $\begin{array}{l}\text { RUK } \\
\text { Capital }\end{array}$ & $\begin{array}{l}\text { RUK- } \\
\text { ROW }\end{array}$ & \\
\hline \multicolumn{10}{|l|}{ Pollution generated in: } \\
\hline Scotland & 21.9 & 4.5 & 2.3 & 8.0 & 8.0 & 0.9 & 1.5 & 1.8 & 48.9 \\
\hline RUK & 6.4 & 1.4 & 2.2 & 2.6 & 328.3 & 36.7 & 48.9 & 89.0 & 515.5 \\
\hline Total (UK) emissions supported by & 28.3 & 5.9 & 4.5 & 10.7 & 336.3 & 37.6 & 50.4 & 90.8 & 564.4 \\
\hline \multicolumn{10}{|l|}{ Environmental trade balance: } \\
\hline Scot pollution supported by RUK final demand & 12.2 & & & & & & & & \\
\hline RUK pollution supported by Scot final demand & 12.6 & & & & & & & & \\
\hline Scotland's CO2 trade surplus & -0.4 & & & & & & & & \\
\hline
\end{tabular}


Table 2. Sectoral Breakdown of the Scot/ RUK Inter-regional IO System

\begin{tabular}{|l|l|l|}
\hline \multicolumn{2}{|c|}{ Scot/RUK sector } & IOC \\
\hline 1 & MANUFACTURING & $1-84,88$ \\
\hline 2 & UTILITIES & $85-87$ \\
\hline 3 & SERVICES & $\mathbf{8 9 - 1 2 3}$ \\
\hline
\end{tabular}

Table 3. Simulation set-ups

\begin{tabular}{|l|l|l|}
\cline { 2 - 3 } \multicolumn{1}{c|}{} & Population & $\begin{array}{c}\text { Regional Wage } \\
\text { Setting }\end{array}$ \\
\hline Quasi OI & $\begin{array}{c}\text { Fixed at the } \\
\text { regional level }\end{array}$ & Fixed real wage \\
\hline $\begin{array}{l}\text { Regional } \\
\text { Bargaining }\end{array}$ & $\begin{array}{c}\text { Fixed at the } \\
\text { regional level }\end{array}$ & Bargaining \\
\hline Flow Migration & $\begin{array}{c}\text { Fixed at the } \\
\text { national level }\end{array}$ & Bargaining \\
\hline
\end{tabular}


Table 4. Summary long run impacts of RUK export demand stimulus on the Type 1 CO2 Trade Balance be twe en Scotland and RUK under three labour market scenarios (\% change from base year values)

\begin{tabular}{|c|c|c|c|}
\hline & Quasi IO & Bargaining & Flow Migration \\
\hline \multicolumn{4}{|l|}{ Pollution generated in: } \\
\hline Scotland & $1.20 \%$ & $0.22 \%$ & $-0.65 \%$ \\
\hline RUK & $3.16 \%$ & $1.22 \%$ & $1.31 \%$ \\
\hline UK & $2.99 \%$ & $1.13 \%$ & $1.14 \%$ \\
\hline \multicolumn{4}{|l|}{ Environmental trade balance: } \\
\hline Scot pollution supported by RUK final demand & $3.04 \%$ & $1.69 \%$ & $0.75 \%$ \\
\hline RUK pollution supported by Scot final demand & $0.60 \%$ & $-1.43 \%$ & $-1.59 \%$ \\
\hline Scotland's CO2 trade surplus/deficit & $-69.76 \%$ & $-91.24 \%$ & $-69.06 \%$ \\
\hline
\end{tabular}


Table 5. Long run impact of RUK export demand stimulus on the Type I CO2 Trade Balance Between Scotland and RUK

(\% change from base year values) - Flow Migration

\begin{tabular}{|c|c|c|c|c|c|c|c|c|c|}
\hline & \multicolumn{8}{|c|}{ Pollution supported by: } & \multirow{2}{*}{$\begin{array}{l}\text { Total regional } \\
\text { emissions of } \\
\mathrm{CO} 2\end{array}$} \\
\hline & $\begin{array}{l}\text { Scottish } \\
\mathrm{HH}\end{array}$ & $\begin{array}{l}\text { Scottish } \\
\text { Govt }\end{array}$ & $\begin{array}{l}\text { Scottish } \\
\text { Capital }\end{array}$ & $\begin{array}{l}\text { Scot- } \\
\text { ROW }\end{array}$ & $\begin{array}{l}\text { RUK } \\
\text { HH }\end{array}$ & $\begin{array}{l}\text { RUK } \\
\text { Govt }\end{array}$ & $\begin{array}{l}\text { RUK } \\
\text { Capital }\end{array}$ & $\begin{array}{l}\text { RUK- } \\
\text { ROW }\end{array}$ & \\
\hline Pollution generated in: & & & & & & & & & \\
\hline Scotland & $-0.82 \%$ & $-0.14 \%$ & $-1.20 \%$ & $-2.45 \%$ & $0.33 \%$ & $-0.84 \%$ & $-0.26 \%$ & $4.27 \%$ & $-0.65 \%$ \\
\hline RUK & $-1.20 \%$ & $-0.41 \%$ & $-1.58 \%$ & $-3.15 \%$ & $0.78 \%$ & $-0.34 \%$ & $0.03 \%$ & $5.06 \%$ & $1.31 \%$ \\
\hline Total (UK) emissions supported by & $-0.91 \%$ & $-0.20 \%$ & $-1.38 \%$ & $-2.63 \%$ & $0.77 \%$ & $-0.35 \%$ & $0.02 \%$ & $5.04 \%$ & $1.14 \%$ \\
\hline Environmental trade balance: & \multicolumn{4}{|c|}{ Tonnes, millions } & & & & & \\
\hline Scot pollution supported by RUK final demand & $0.75 \%$ & 12.30 & & & & & & & \\
\hline RUK pollution supported by Scot final demand & $-1.59 \%$ & 12.44 & & & & & & & \\
\hline Scotland's CO2 trade surplus & $-69.1 \%$ & -0.13 & & & & & & & \\
\hline
\end{tabular}




\section{Figures}

Figure 1. Impact of the increase in ROW export demand for RUK Manufacturing on the outputs of each production sector in Scotland and RUK
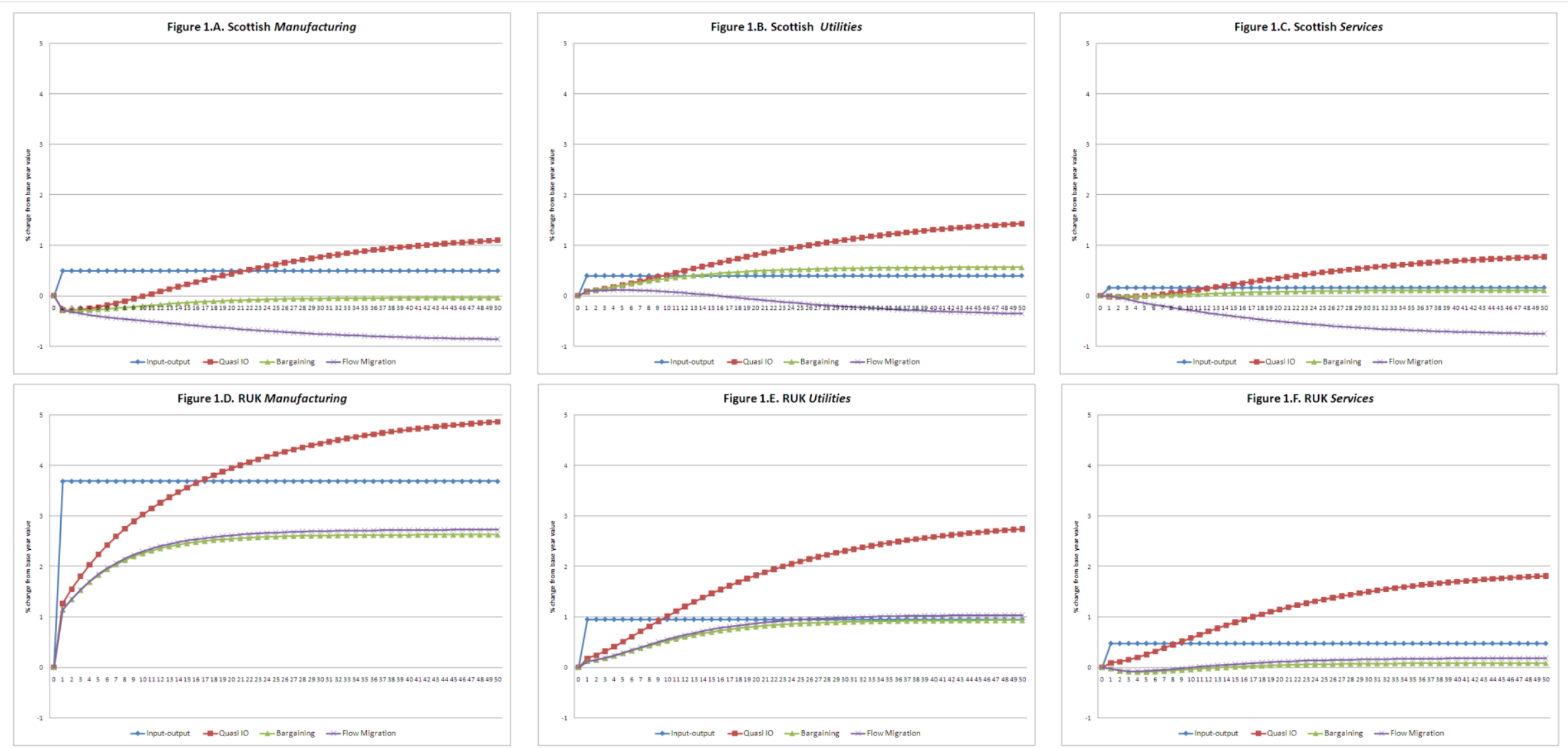
